\title{
Filistorias
}

\section{Blackout e a Luftwaffe nazista: Algumas notícias da II Grande Guerra na cidade}

\author{
de Manaus - AM ${ }^{1}$
}

Sidney Barata de Aguiar $^{2}$

DOI: 10.26512/emtempos.v1i33.23543

RESUMO: A base naval de Pearl Harbor ardeu em chamas durante o ataque inesperado de forças militares do Japão (1941). Com esta investida, o império nipônico dominava o sudeste asiático e suas ricas plantações de seringueiras na Malásia. Com isto, a economia da borracha brasileira seria reaquecida, a partir da assinatura dos chamados Tratados de Washington, colocando a Amazônia no tabuleiro as II Guerra Mundial (1939 - 1945). Na cidade de Manaus, capital do Estado do Amazonas, os jornais publicavam notícias sobre o conflito mundial e medidas para os habitantes se protegerem de possíveis confrontos diretos. O perigo de um verdadeiro ataque das forças nazistas sobre a Hinterlândia amazônica pairava no ar.

\section{PALAVRAS-CHAVE: Blackout; Borracha; Manaus.}

ABSTRACT: The Pearl Harbor naval base burst into flames during an unexpected attack of Japan's military forces (1941). With this onslaught, the Japanese Empire dominated South-East Asia and its rich plantations of rubber trees in Malaysia. With this, the economy of brazilian rubber would be reheated, from the signature of the treaties of Washington, putting the Amazon on the Board the World War II (1939-1945). In the city of Manaus, capital of Amazonas State, newspapers published news about the world conflict and measures to protect residents from possible direct confrontations. The danger of a real attack of Nazi forces on the Amazon Hinterland hovered in the air.

KEYWORDS: Blackout; Rubber; Manaus.

“As luzes se apagam em toda a Europa”, disse Edward Grey, secretário das Relações Exteriores da Grã-Bretanha, observando as luzes de Whitehall na noite em que a Grã-Bretanha e a Alemanha foram à guerra.

Eric Hobsbawm

\footnotetext{
${ }^{1}$ Este trabalho faz parte da Dissertação de Mestrado Arigós, Jabá e o Caso da Carne Verde: vivências populares na cidade de Manaus (1939 - 1949) defendida no âmbito do Programa de Pós-Graduação em História (PPGH) da Universidade Federal do Amazonas (UFAM) e orientada pelo Professor Dr. Marcos Borges da Silveira (UFPel) no ano de 2012. O trabalho sofreu diversas supressões e/ou acréscimos para ficar compreensível e palatável na forma de artigo científico aqui apresentado.

2 Doutorando pelo Programa de Pós-Graduação Sociedade e Cultura na Amazônia (PPGSCA) da Universidade Federal do Amazonas (UFAM). Mestre em História Social pelo Programa de Pós-Graduação em História (PPGH) da Universidade Federal do Amazonas (UFAM). Especialista pelo Programa de PósGraduação Lato Sensu em Desenvolvimento, Etnicidade e Políticas Públicas na Amazônia (DEPPA) do IFAM - CMZL (Instituto Federal de Educação, Ciência e Tecnologia do Amazonas - Campus Manaus/Zona Leste). Professor das redes públicas de educação do estado do Amazonas e do município de Manaus. Contato: sidneybaratadeaguiar@gmail.com
} 
Quando as primeiras bombas e torpedos atingiram a sonolenta base naval norteamericana de Pearl Harbor (1941), localizada no arquipélago do Havaí, abriu-se o caminho para o Japão conquistar todo o sudeste asiático e suas plantações de borracha na Malásia (NETO, 2000, p. 33-34).

Desta forma, as forças armadas nipônicas efetuavam um passo importante no desenrolar da contenda que se tornaria realmente mundial com a participação das tropas estadunidenses (HOBSBAWM, 1995, p. 31).

Este episódio reaqueceria a economia gomífera da região amazônica. Depois deste fato, foi criado um considerável aparato logístico-institucional, celebrados pelos chamados Acordos de Washington durante o Estado Novo de Getúlio Vargas (1937 1945).

Com a assinatura do termo de beligerância em 31 de agosto de 1942, o Brasil declarava guerra contra os países do Terceiro Eixo (Alemanha, Itália e Japão), dentre estas medidas, estava o que se convencionou denominar de Esforço de Guerra para os brasileiros e brasileiras.

Para este libelo, pesquisamos alguns periódicos para dar substância a nossas proposições. Utilizar a imprensa escrita para o trabalho do historiador e historiadora já se tornou singular, apesar das críticas feitas ao longo do debate historiográfico desde a década de 1970 (LUCA, 2008, p. 111).

Para uma melhor compreensão sobre o impacto deste capítulo da História no Estado do Amazonas, recorremos ao estudo de Luiz de Miranda Corrêa, “A Borracha do Amazonas e a segunda Guerra Mundial” (1965). A obra demonstra como a refrega internacional, iniciada em terras europeias sofreu quase um colapso pela escassez do látex da seringueira como matéria-prima da indústria bélica dos países aliados (Estados Unidos, Inglaterra e Rússia)

Uma observação importante de Corrêa aponta para a montagem de uma infraestrutura com diversas empresas brasileiras, estadunidense ou mistas, todas elas voltadas e dedicadas a responder a rápida produção para suprir a demanda de borracha (1965).

A produção, o armazenamento e a exportação de borracha necessitavam de uma mão-de-obra barata e disponível para esta empreitada. Novamente os nordestinos. 
Frequentemente, oriundos de regiões castigadas pelo fenômeno das secas ininterruptas foram “alistados” para tornarem-se Soldados da Borracha.

Para este "recrutamento" de mão-de-obra de nordestinos para os seringais (locais onde estão as árvores chamada Seringueiras) da Amazônia, era o SEMTA (Serviço Especial de Mobilização de Trabalhadores para a Amazônia), que possuía o controle e a política de “recrutamento” e do trânsito destes migrantes entre as regiões nordeste e norte.

Além da propaganda institucional massiva por parte das autoridades, a estação seca contínua em 1942 que assolou tragicamente muitos estados do nordeste brasileiro criou as condições necessárias para a atração de milhares de sertanejos para os rios amazônicos.

Pelas ondas do rádio e da tela grande do cinema, a maioria dos manauaras ficavam atentos às últimas notícias sobre o conflito bélico mundial.

Além das ondas radiofônicas e dos filmes da indústria audiovisual dos norteamericanos, outro meio de comunicação importante para a informação da população local eram os jornais impressos. E durante este período em tela, a imprensa escrita tinha um papel preponderante. Saber das movimentações nos “teatros de guerra” em diversas partes do mundo era algo de espírito patriótico potencializado.

Além do mais, os aviões de Adolf Hitler poderiam a qualquer momento bombardear o norte do país.

O comunicado VII da Defesa Passiva Anti-aérea relata as diretrizes de ação preventiva para os manauaras e como deveriam colocar em prática os procedimentos exatos diante da atividade miliar conhecida como Blackout. Nesta ação, todas as luzes eram apagadas ao mesmo tempo para dificultar a visualização aérea noturna de possíveis sobrevoos ou ataques de aeronaves hostis.

Este comunicado deixa claro, que o perigoso descuido de deixar uma única residência iluminada, poderia "arrazar uma cidade”. ${ }^{3}$

\footnotetext{
${ }^{3}$ A TARDE, 04 de agosto de 1942, terça-feira, $N^{\circ}$ 1.661, Ano VI.
} 
A manobra do blecaute foi colocada em prática na cidade de Manaus em 18 de agosto do ano de $1942^{4}$. Sob a orientação do Coronel Gontran Jorge Pinheiro Cruz, então comandante do $27^{\circ}$ Batalhão de Caçadores.

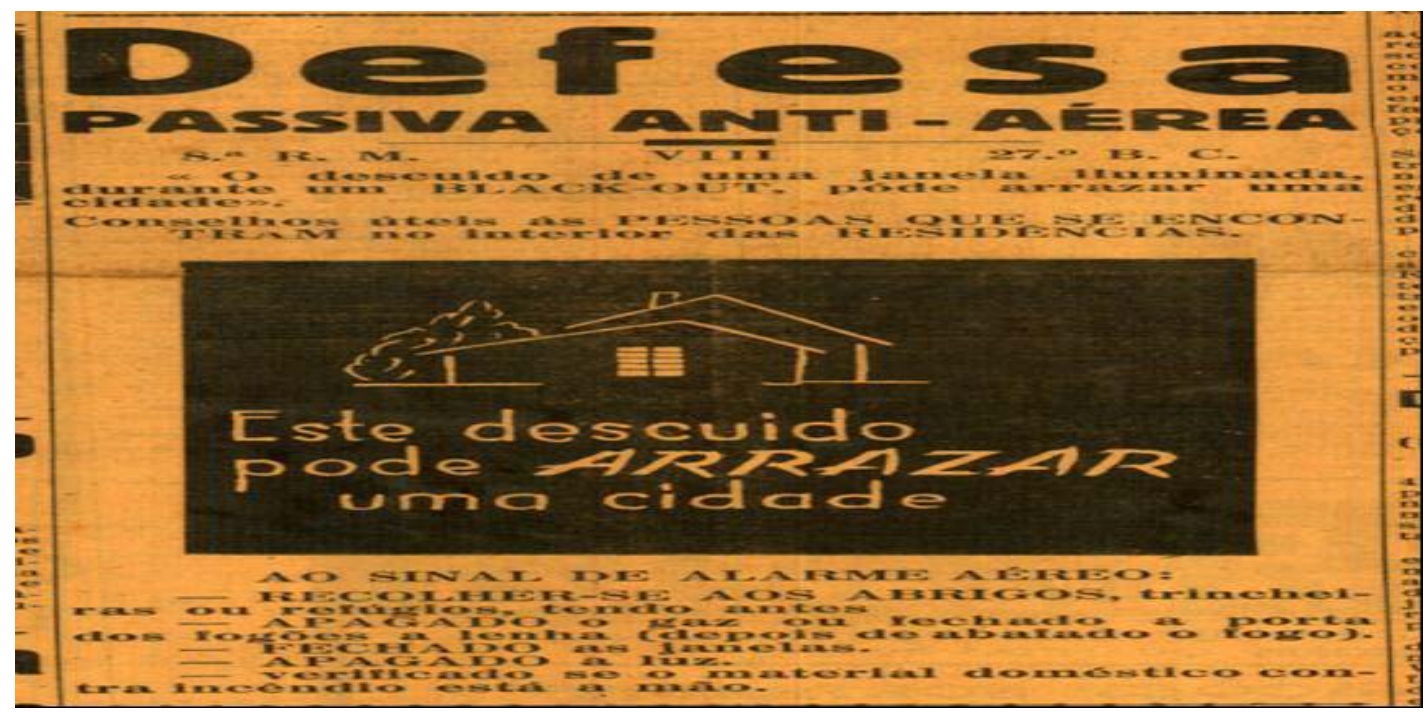

Figura 01: A TARDE, 04 de agosto de 1942, terça-feira, $N^{\circ}$ 1.661, Ano VI.

Desta forma foram divulgadas um sistema de educação, orientações para a disciplina da consciência coletiva, instruções preparatórias para o exercício de defesa antiaérea. Utilizando a área privilegiada do Teatro Amazonas, o militar de alta patente ordenou que suas patrulhas de soldados fiscalizassem vários trechos da cidade. No vespertino A Tarde, temos um relato, que segundo seus executores, tratou-se de uma ação vitoriosa. Percebam que:

Ás vinte horas e quinze minutos foram ouvidos os sinais de alarme. A Manaus Tramways imediatamente apagou a chave geral da iluminação da cidade. As casas particulares cerraram suas portas e apagaram as luzes. A cidade ficou em completo silêncio. Parecia que dormia. ${ }^{5}$

Era necessário educar e treinar nestes exercícios o maior número de civis, pois ao desligar a chave geral de eletricidade ainda, muitas pessoas que residiam nos

\footnotetext{
${ }^{4}$ A TARDE, 19 de agosto de 1942, quarta-feira, $N^{\circ}$ 1.674, Ano VI.

${ }^{5}$ A TARDE, 19 de agosto de 1942, quarta-feira, $N^{\circ} 1.674$, Ano VI.
} 
arrabaldes utilizavam outras formas de iluminar a escuridão como fogueiras, lampiões e lamparinas.

Esse efeito psicológico era reforçado pela organização da Liga de Defesa Passiva Anti-aérea que distribuía folhetos e notas nos matutinos e vespertinos instruindo a população sobre o comportamento seguro em caso de possíveis bombardeios.

A orientação principal era a constituição de um Serviço Doméstico Contra Incêndios em cada habitação que deveria ser composto por pessoas sadias, dispostas a enfrentar riscos e possuindo material de urgência como areia e baldes de água para o enfrentamento dos momentos de emergência.

Dentre estas advertências úteis aos pedestres em trânsito nas ruas e surpreendidos pelo sinal de alarme deveriam: manter a calma, abrigarem-se nas construções mais próximas (igrejas e edifícios públicos), cessar o trânsito de automóveis e no caso de encontrar-se em áreas descobertas deitar de bruços no chão. ${ }^{6}$

Em Manaus todos os que participaram do Curso Regional de Defesa Passiva Anti-aérea receberam certificados de eficiência e eram convocados para fiscalizar o exercício de blackout determinado. ${ }^{7}$

Esta mobilização em defesa da pátria concretizava-se na realização de medidas tomadas por instituições dos Estados e municípios.

Para Jorgemar Monteiro (2010), a primeira iniciativa de treinamentos em bairros com os cidadãos partiu do Corpo de Bombeiros do Rio de Janeiro em 15 de abril de 1942. Segundo o autor esta empreitada tinha como objetivo, "preparar a população para a defesa contra ataques aéreos com bombas incendiárias, técnica bastante utilizada naquela guerra. Os bombeiros tinham como práticas diárias, entre outras tarefas, treinar a população civil no caso de eventuais bombardeios” (2010, p. 89).

Nesta nota, o que mais chama à atenção, são as indicações para os proprietários de automóveis. Uma delas aponta para a necessidade de cobrir os faróis com tecido negro ou pintá-los com tinta escura, deixando apenas um pequeno orifício no farol esquerdo. ${ }^{8}$

\footnotetext{
${ }^{6}$ A TARDE, 01 de agosto de 1942, sábado, N 1.659, Ano VI.

${ }^{7}$ A TARDE, 19 de maio, quarta-feira, $\mathrm{N}^{\circ} 1.897$, Ano VII.

${ }^{8}$ A TARDE de 12 de outubro de 1943, terça-feira, $N^{\circ} 2.011$, Ano VII.
} 
O Capitão Instrutor que assinou este documento foi Manoel Expedito Sampaio que também orientava aos cavalheiros o trajar roupas brancas ou o uso de lenço branco envolto no pescoço e fita branca nos chapéus. As senhoras deveriam usar vestimentas claras ou uma faixa alva na cintura, tudo isto para melhor visualização na escuridão.

No dia seguinte, a nota publicada, diz respeito aos manauaras que estejam em suas casas durante os ataques diurnos. Estes moradores devem fechar totalmente janelas, portas e manter distância destes, além de fixarem reposteiros e cortinas escuras.

No caso da pessoa estiver em casa de conhecido, deverá abrigar-se neste domicílio e alerta para o maior prejuízo, estar privado da máscara contra gazes. Também são orientados a desligarem todas as chaves do gás de cozinha e da distribuição de água encanada. ${ }^{9}$

Quando na sua própria residência e não havendo abrigo seguro, era aconselhável esconder-se embaixo dos considerados móveis resistentes como mesas e camas.

A conduta correta para os cidadãos ao cessar um ataque aéreo com bombas explosivas e incendiárias, era preciso retornar imediatamente as residências ou locais de trabalho e em hipótese alguma, deveriam aproximar-se ou tocar nos artefatos explosivos intactos e não detonadas.

No caso de um ataque que utilize armas químicas as instruções também surpreendem. Após o fim do “alérta aéreo-químico”, todos deveriam abandonar os abrigos com calma. As residências infectadas pelos "agressivos químicos" seria comunicado imediatamente às autoridades policiais do distrito mais próximo. A partir deste primeiro procedimento, o "Serviço de Desinfectadores” entraria em ação. Eles certificavam-se da presença do "agressivo”, qual sua natureza e só então, colocariam em prática o processo de neutralização do veneno. ${ }^{10}$

O cidadão também poderia contribuir com este processo de desinfecção, pulverizando uma solução de cinquenta gramas de carbonato de sódio misturado em 01 litro de água em todos os móveis do ambiente. A nota também alerta para a não ingestão

\footnotetext{
${ }^{9}$ A TARDE de 13 de outubro de 1943, quarta-feira, $N^{\circ} 2.012$, Ano VII.

${ }^{10}$ A TARDE de 15 de outubro de 1943, sexta-feira, № 2.014, Ano VII.
} 
de água ou qualquer alimento com o menor indício de contaminação. O contato com qualquer objeto da casa só seria permitido com a utilização de uma luva impermeável. ${ }^{11}$

No Quartel da Força Policial do Estado em seu pátio interno, sob a direção do Major Gonzaga Pinheiro, realizou-se o segundo exercício de salvamento contra incêndios provocados por ataques aéreos. Executaram-se provas práticas ministradas por militares e soldados do Corpo de Bombeiros. ${ }^{12}$

Em 1943, o Dr. Rui Araújo na pasta de Secretário Geral do Estado do Amazonas e chefe do Serviço de Defesa Passiva Anti-aérea em sintonia com o capitão Luiz França também empreenderam um blecaute que teve uma extensão de todo o território nacional, que segundo os jornais apresentou alguns problemas.

Nos bairros de São Raimundo e Educandos uma serraria e uma fábrica mantiveram suas luzes acesas por muito tempo, fato resolvido com a intervenção dos fiscais ${ }^{13}$. Mesmo assim, houve o escurecimento total da cidade com uma duração mínima de 2 horas e anunciado pelos apitos das fábricas, badaladas dos sinos dos templos religiosos, sirenes dos jornais e o apitar das embarcações ancoradas no porto, no igarapé de Manaus e na orla dos bairros de São Raimundo e Educandos. ${ }^{14}$

Neste mesmo ano de 1943, temos a informação de uma operação de "Guerra Simulada”, ou seja, um plano orquestrado de combate que os soldados utilizaram fuzis e metralhadoras com munição de festim, este teatro de operações se desenrolou nas proximidades do bairro de São Raimundo. ${ }^{15}$

Com os inúmeros torpedeamentos de navios nacionais na costa brasileira por submarinos alemães, criou-se um clima de acirramento e animosidade contra os cidadãos dos países que formavam o III Eixo.

Uma destas embarcações levada a pique foi o paquete Baependy que rotineiramente fazia o percurso Manaus ao Rio de Janeiro e fora torpedeado no Atlântico. Neste trágico incidente, vários amazonenses perderam a vida. Este fato corroborou para

\footnotetext{
${ }^{11}$ A TARDE de 15 de outubro de 1943, sexta-feira, $N^{\circ} 2.014$, Ano VII.

12 A TARDE de 09 de abril de 1943, sexta-feira, $N^{\circ} 1.866$, Ano VII.

${ }^{13}$ A TARDE de 05 de maio de 1943, quarta-feira, $N^{\circ} 1,885$, Ano VII.

${ }^{14}$ A TARDE de 17 de junho de 1943, quinta-feira, $N^{\circ} 1.992$, Ano VII.

${ }^{15}$ A TARDE de 14 de abril de 1943, quarta-feira, $N^{\circ} 1.870$, Ano VII.
} 
atitudes violentas contra quem estivesse próximo das nações "germanófilas”. Jefferson Péres (2002) assim relata:

Como ainda não havia japoneses, concentrados que estavam no baixo Amazonas, a fúria popular se abateu sobre os bens de italianos, alemães e pessoas de qualquer nacionalidade conhecidas como germanófilas. $\mathrm{O}$ primeiro alvo foi o consulado da Alemanha, situado na Joaquim Nabuco, nos altos do prédio de dois pavimentos, que ainda hoje existe, próximo à avenida 7 de Setembro, onde vi muitas vezes desfraldada a bandeira alemã com a suástica. Fui testemunha ocular do saque ao consulado, que é das mais remotas lembranças de infância (2002, p. 59$60)$.

Quanto aos japoneses, têm-se notícias da presença dos Koutakuseis ${ }^{16}$ no início da década de 1930 nos municípios de Maués e Parintins trabalhando nas plantações de guaraná e juta, respectivamente. Posteriormente, temos a fundação da Colônia Bela Vista que abrangia uma grande extensão até o município de Manacapuru e da Colônia Efigênio Salles. ${ }^{17}$

Na época da Segunda Guerra, muitos japoneses foram encaminhados para lugares similares a “campos de concentração”, além da reclusão, também tiveram suas terras confiscadas e leiloadas. Ao ponto que o deputado Tsukasa Uetsuka, um dos maiores entusiastas e incentivadores da migração nipônica para o Brasil tentou reverter o arremate das propriedades, mas já era tarde demais.

O clima de perseguição desembocou em depredações cometidas por hordas nervosas e quase sempre, incontroláveis.

As hostilidades verbais eram comuns e eram manifestadas por "insulto aberto, da negativa de cumprimento, ou de denúncias anônimas e nunca comprovadas de quintacolunismo” (PÉRES, 2002, p. 63). Assim, temos em uma revista bastante conhecida na cidade de Manaus:

\footnotetext{
${ }^{16}$ Docentes da recém fundada Kokushikan Koutou Takushoku Gakkou que na língua portuguesa significa Escola Superior de Colonização.

${ }^{17}$ Para um estudo mais sólida verificar em KAWADA, Takuya. Histórico da Imigração Japonesa no Estado do Amazonas. Edição comemorativa do Centenário do Tratado de Amizade, Comércio e Navegação Brasil - Japão, 1895 - 1995. Obra patrocinada pela Federação das Indústrias do Estado do Amazonas (FIEAM).
} 
ALERTANDO OS BRASILEIROS CONTRA 0 QUINTA COLUNISMO

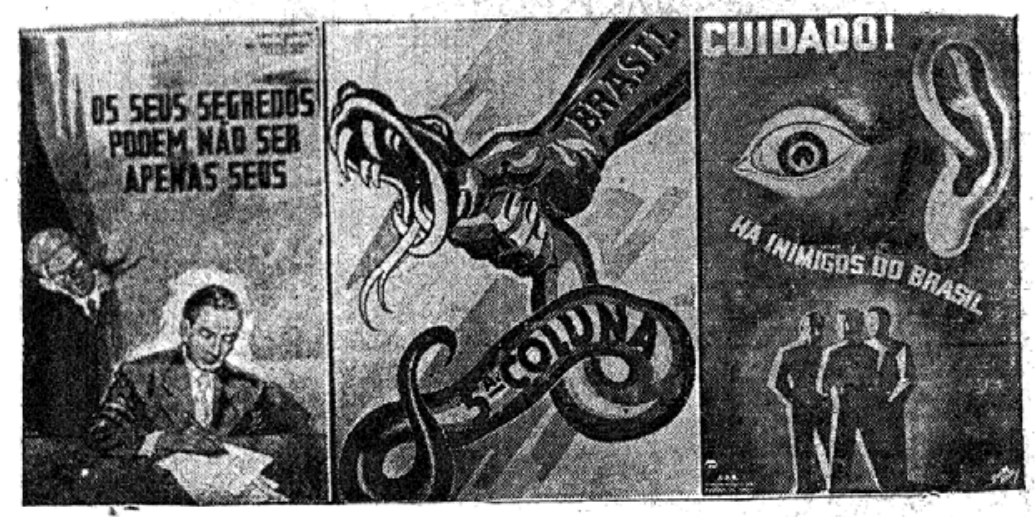

Na gravura estáo reproduzidos três cartazes de propaganda contra a "quinta coluna", iniciativa particular que recebeu a aprovaçáo do Departamento de Imprensa e Propaganda. No momento em que o Governo póe em execuçâo medidas preventivas da açao dos inimigos do Brasil, nem é preciso encarecer o valôr dessa propaganda inteligente e inersiva que visa elertar todos os brasileiros contra as manobras funestas dos quintacolunistas, aos quais a Naçâo já deve tantos momentos de angustia e de lutas como no caso do afundamento de nossos navios.

("Diario da Tarde", Manaus, 16/5,42),

Figura 02: Campanha contraespionagem do DIP. Fonte: Revista Amazonida, Manaus - maio de 1942, $n^{\circ}$ 63, ano VII.

Na gravura encontramos três cartazes do DIP que traziam mensagens de atenção e combate contra a espionagem de estrangeiros. Com cuidado maior para cidadãos alemães, japoneses e italianos. No primeiro cartaz, os dizeres alertam para homens que possuem comportamentos estranhos e que escondem segredos, ou seja, informações sobre o Brasil.

Na segunda imagem os espiões são representados por uma víbora, que na tradição cristã representa a traição e o braço forte do Estado Novo asfixia a serpente como cautela e defesa da nação brasileira.

Para finalizar, temos homens na penumbra em situação suspeita, ao que tudo indica tramando alguma coisa muito perigosa. As letras garrafais alertam para a presença de "Inimigos do Brasil” e por isto, todos os brasileiros deveriam estar de olhos e ouvidos bem abertos.

O papel de extrema importância desempenhado pela imprensa escrita e revistas nos períodos autoritários como o Estado Novo e a militar devem ser observados da forma de difusor da propaganda política a favor dos regimes (LUCA, 2008, p. 129).

Toda esta massiva propaganda contra o quinta-colunismo, também incentivaria a denúncia anônima, a delação contra estas "manobras funestas”. 
Um exemplo ocorreu com um imigrante que foi obrigado a modificar o alusivo nome de sua propriedade na rua Vinte e Quatro de Maio (Centro de Manaus) de Vila Itália para uma homenagem aos que sofreram ataques dos submarinos alemães, ou seja, tornouse Vila Baependi (PÉRES, 2002, p. 63).

Em diversas capitais brasileiras estas hostilidades, agressões e incêndios criminosos também foram registrados (DULLES, 1979, p. 248).

O embate ideológico também se fazia presente, tenho o exemplo de uma entidade que preconizava o combate severo contra todos aqueles que estivessem próximos das nações do Eixo. A Liga Amazonense Contra o Eixo (LACE) pregavam a vigilância constante e a posição irredutível na missão de sacrificar tudo em defesa da honra e da dignidade do país. Seu símbolo era a letra V em cores nacionais. No seu estatuto em trechos publicados em agosto de 1942 eles defendiam:

I- Empregar todos os meios intelectuais, morais e matéria; no combate ao eixo, representados pelas nações que o compõem ou outras que surgirem com os mesmos princípios de barbárie, embora com rótulos diferentes.

II- Evitar precipitações ou julgamentos prematuros, de pessoas nazistas ou quinta-colunistas, e somente depois de apurado procedimento ou atividades contrárias aos interesses nacionais, denuncia-las, legalmente, na forma da lei. ${ }^{18}$

Vale ressaltar que em período que abrange principalmente a segunda metade do ano de 1943 no vespertino. No periódico A Tarde é frequente a presença de charges utilizando o humor para ridicularizar os principais líderes do Eixo: Mussolini e Hitler.

\footnotetext{
${ }^{18}$ A TARDE de 15 de agosto de 1942, sábado, № 1.671, Ano VI.
} 


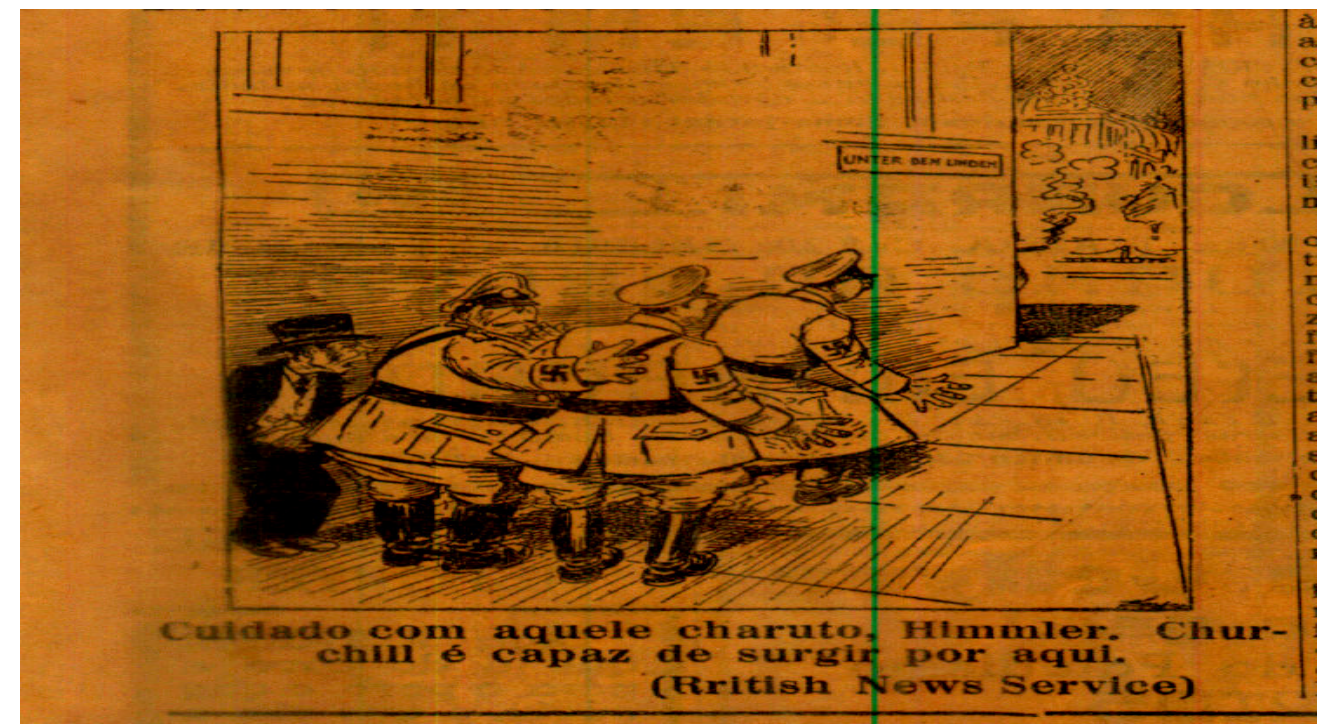

Figura 03: A TARDE de 15 de agosto de 1942, sábado, № 1.671, Ano VI.

As gravuras são divulgadas pelo Serviço de Notícias Inglês, por isso a imagem do Primeiro-Ministro britânico Winston Churchill (1874 - 1965) está vinculada com a vitória e no caso abaixo, o pavor dos generais alemães só ao observarem a fumaça do charuto que sempre o acompanhou. O aviso direto a Heinrich Himmler era proposital, pois era considerado um dos oficiais mais poderosos da Alemanha. Liderou a $\mathrm{SS}^{19}$ e também assumiu o posto de comandante da Gestapo. ${ }^{20}$

Retomando as referências de memorialistas que subsidiam nossa escrita, retorno em Jefferson Péres (2002), que viveu este período conturbado da história local. O desconforto causado pela falta de gêneros básicos de todos os tipos era somado ao "temor fantasioso" de possíveis ataques aéreos da aviação germânica em terras amazonenses (2002, p. 63).

A Deutsche Luftwaffe ou Força Aérea Alemã foi fundamental na estratégia de conquista da Europa Oriental e Ocidental. Mostrou-se uma arma poderosa a favor dos nazistas e seu símbolo que estampavam todas as aeronaves era a Cruz de Ferro.

\footnotetext{
${ }^{19}$ Iniciais de Schutszataffel ou Esquadrão de Proteção, tratava-se da guarda de elite do Partido Nazista um ótimo trabalho sobre o tema encontra-se em WILLIAMSON, Gordon. A SS: O instrumento de terror de Hitler: A história completa, desde combatentes de rua até as Waffen-SS / Gordon Williamson; tradução Roberson Melo. - São Paulo: Editora Escala, 2008.

${ }^{20}$ Siglas de Geheime Staats Polizei ou Polícia Secreta do Estado do regime hitlerista. Para mais informações temos a obra de BUTLER, Rupert. A Gestapo: A história da polícia secreta de Hitler: 19331945 / Rupert Butler; tradução Emanuel Mendes Rodrigues. - São Paulo; Editora Escala, 2008.
} 
Mesmo assim, a autonomia de voo destas máquinas de guerra mortais era limitada e o oceano que nos divide com a Europa é gigantesco e foi preponderante para que os alemães não chegassem tão perto pelo ar a ponto de disparar contra o solo brasileiro.

Também foi nas páginas dos matutinos e vespertinos que a população amazonense ficou a par do armistício do embate que se arrastava e que tinha nas águas do Pacífico o desenrolar dos seus últimos capítulos.

Segundo Ediney Azancoth as notícias radiofônicas "não chegavam até a população pobre” e ao ouvir o soar das sirenes do Jornal do Commercio e de O Jornal que ficavam na Avenida Eduardo Ribeiro, os habitantes corriam e sobre cotoveladas e formando pequena multidão foram surpreendidos pelas notas expostas nos murais em frente das respectivas redações: "A bomba atômica foi lançada sobre Hiroxima e Nagasaki! O Japão rende-se! A guerra acabou!” (2010, p. 87 - 88).

\section{CONCLUSÃO}

Com a vitória dos países aliados ficou demarcada a recuperação e o domínio das áreas coloniais do Sudeste Asiático. E esta região em pouco tempo retorna ao posto de grande produtora mundial do "leite da seringueira".

Os dirigentes norte-americanos fecharam definitivamente “as torneiras" de investimentos na Amazônia em 30 de julho de 1947.

A Rússia depois de adentrar as portas de Berlim na Alemanha também investe pesado na recuperação de sua indústria e a borracha sintética terá um papel imensurável para a reconstrução de sua economia.

Quanto ao caso brasileiro e especificamente a Amazônia tem um crescimento de excedentes do látex durante alguns anos. Consequentemente, não houve uma absorção da borracha por um mercado consumidor interno e o cerceamento de créditos para a produção nos seringais foi gradativamente retirados, sufocando ainda mais, uma economia que já apresentava fragilidade. 
A riqueza do látex da borracha novamente escorreria pelos nossos dedos, anunciando mais um período de estagnação e letargia econômica e social. O Amazonas passa a sobreviver com a atividade da pesca e a extração da castanha do Brasil, juta, madeiras, especiarias e outros produtos provenientes da floresta.

Repetia assim, os mesmos erros primários do período da Belle Èpoque (primeira década do século XX). Não levando em consideração o axioma (válido ou não válido) que diz que a História serve para que não cometamos os mesmos erros do passado.

O colapso econômico foi tão brutal que a economia do Estado do Amazonas só retornou a ter um verdadeiro fôlego com a implantação da Zona Franca de Manaus e o Polo industrial de Manaus no final da década de 1960. Trazendo consigo as invasões de terras urbanas, criminalidade descontrolada, péssima infraestrutura, todos os problemas característicos sofridos pelas grandes cidades. Problemas superlativados encontrados na Metrópole dos Manaós. Mas este é outro capítulo da nossa História.

Quanto aos "Soldados da Borracha” e suas famílias, somente na elaboração da Constituição Brasileira de 1988 e com a Emenda Constitucional 78 promulgada no ano de 2014, foram parcialmente, reconhecidos pelos seus esforços e o direito a receber uma modesta aposentadoria de dois salários mínimos e uma indenização pecuniária. Pior que sobreviver com esta injusta situação financeira, é ter que continuar o combate, desta vez, no front do esquecimento da História da Amazônia e do Brasil.

Este trabalho objetivou fazer alguns apontamentos sobre este período tão conturbado na cidade de Manaus e no Estado do Amazonas. Esta é uma parte da história do período da II Guerra Mundial que sem dúvida alguma, assemelha-se aos melhores escritos do gênero de narrativa dos romances sobre espionagem.

\section{REFERÊNCIAS BIBLIOGRÁFICAS}

AZANCOTH, Ediney. Os anos em que vivemos na escuridão. In: MARINHO, José Joaquim Marques (Org.). Manaus, meu sonho. Manaus: Editora Valer, Prefeitura de Manaus, ManausCult, 2010.

BUTLER, Rupert. A Gestapo: A história da polícia secreta de Hitler: 19331945 / Rupert Butler; tradução Emanuel Mendes Rodrigues. - São Paulo; Editora Escala, 2008.

CORRÊA, Luiz de Miranda. A Borracha do Amazonas e a segunda Guerra Mundial (1965). 
DULLES, John Foster. Getúlio Vargas. Rio de Janeiro: Civilização Brasileira, 1979.

HOBSBAWM, Eric J. Era dos extremos: o breve século XX: 1914-1991. São Paulo: Companhia das Letras, 1995.

PÉRES, Jefferson. Evocação de Manaus - como eu a vi ou sonhei. $2^{\circ}$ edição revista e ampliada. Manaus: Editora Valer, 2002.

LUCA, Tania Regina de. História dos, nos e por meio de periódicos. In: PINSKY, Carla Bassanezi, (Org.). Fontes Históricas, $2^{\circ}$ ed. São Paulo: Contexto, 2008.

NETO, José Maria Bezerra. A economia da borracha e o esforço de guerra: Os Soldados da Borracha na Amazônia. In. Pontos de História da Amazônia, volume II, $2^{\circ}$ edição ampliada, - Belém: Paka-Tatu, 2000.

KAWADA, Takuya. Histórico da Imigração Japonesa no Estado do Amazonas. Edição Comemorativa do Centenário do Tratado de Amizade, Comércio e Navegação Brasil - Japão, 1895 - 1995. Obra patrocinada pela Federação das Indústrias do Estado do Amazonas (FIEAM).

VARGAS, Getúlio. Discurso do Rio Amazonas, Amazônia Brasileira (Rio de Janeiro, 1944).

WILLIAMSON, Gordon. A SS: O instrumento de terror de Hitler: A história completa, desde combatentes de rua até as Waffen-SS / Gordon Williamson; tradução Roberson Melo. - São Paulo: Editora Escala, 2008.

SALUN, Alfredo Oscar. "Zé Carioca vai à guerra: histórias e memórias sobre a FEB. São Paulo: Edições Pulsar, 2004.

\section{OUTRAS FONTES}

A TARDE, 04 de agosto de 1942, terça-feira, $\mathrm{N}^{\circ}$ 1.661, Ano VI.

A TARDE, 19 de agosto de 1942, quarta-feira, $N^{\circ} 1.674$, Ano VI.

A TARDE, 01 de agosto de 1942, sábado, N 1.659, Ano VI.

A TARDE, 19 de maio, quarta-feira, $N^{\circ}$ 1.897, Ano VII.

A TARDE de 13 de outubro de 1943, quarta-feira, $N^{\circ}$ 2.012, Ano VII.

A TARDE de 15 de outubro de 1943, sexta-feira, $N^{\circ} 2.014$, Ano VII.

A TARDE de 09 de abril de 1943, sexta-feira, $N^{\circ} 1.866$, Ano VII.

A TARDE de 05 de maio de 1943, quarta-feira, $N^{\circ} 1,885$, Ano VII.

A TARDE de 17 de junho de 1943, quinta-feira, $N^{\circ}$ 1.992, Ano VII.

A TARDE de 14 de abril de 1943, quarta-feira, $N^{\circ} 1.870$, Ano VII.

A TARDE de 15 de agosto de 1942, sábado, N 1.671, Ano VI.

Revista Amazonida, Manaus - maio de 1942, n 63, ano VII. 